\title{
Original and infiltrating patterns of prostatic carcinoma
}

\author{
NOBUKI FURUBAYASHI ${ }^{1}$, MOTONOBU NAKAMURA ${ }^{1}$, KENITI NISHIYAMA ${ }^{2}$ and YOSHIHIRO HASEGAWA $^{1}$ \\ Departments of ${ }^{1}$ Urology and ${ }^{2}$ Pathology, National Kyushu Cancer Center, Fukuoka 811-1395, Japan
}

Received May 8, 2009; Accepted August 19, 2009

DOI: 10.3892/ol_00000007

\begin{abstract}
In order to demonstrate the original and infiltrating patterns of prostatic carcinoma, the change of histological characteristics associated with increasing total cancer volume was investigated. Tissue specimens from 196 histopathological cases, obtained at the Kyushu Cancer Center, were reviewed in embedded whole-mount antegrade radical prostatectomy specimens with adenocarcinoma. Three groups $\left(<0.5 \mathrm{~cm}^{3}, \leq 0.5 \mathrm{~cm}^{3}\right.$ $<1 \mathrm{~cm}^{3}$ and $\geq 1 \mathrm{~cm}^{3}$ ) of total cancer volume were identified and a histological study on each group was conducted based on the 2005 International Society of Urological Pathology Consensus Conference on Gleason Grading of Prostatic Carcinoma. With a cancer volume of $<0.5 \mathrm{~cm}^{3}$, Gleason primary patterns 3 and 4 were observed in 64.4 and $26.7 \%$ of the tumors, respectively, while Gleason secondary patterns 3 and 4 were observed in 53.3 and $42.2 \%$, respectively. The density of the acini was much higher in comparison with that of ambient normal acini. The percentage of acini, including cribriform carcinoma classified as Gleason pattern 3, increased significantly with the increase of cancer volume $(\mathrm{p}<0.01)$. The original pattern of the prostatic carcinoma was histologically composed of small acini of Gleason patterns 3 and 4 without forming a cribriform pattern. In addition, prostatic carcinoma infiltrated the surrounding stroma at a very early stage, thus infiltrating not only the stroma but also the preexisting ducts and acini, causing an increased cancer volume.
\end{abstract}

\section{Introduction}

In recent years, more prostatic carcinoma have been detected at an earlier stage because of the widespread use of prostatespecific antigen and transrectal ultrasonography-guided systematic biopsy. Therefore, a low cancer volume has been increasingly observed in radical prostatectomy specimens. Despite this observation, the true natural history of prostatic carcinoma remains largely uncertain (1). Subsequently, this

Correspondence to: Dr Nobuki Furubayashi, Department of Urology, National Kyushu Cancer Centre, Notame 3-1-1, Minami-ku Fukuoka 811-1395, Japan

E-mail: furubayashi.n@nk-cc.go.jp

Key words: prostatic carcinoma, low cancer volume, original pattern, infiltrating pattern, Gleason pattern 3 cribriform carcinoma study investigated the change of histological characteristics associated with increasing total cancer volume to demonstrate morphological original and infiltrating patterns of prostatic carcinoma which increase total cancer volume.

\section{Materials and methods}

Tissue specimens from 248 histopathological cases, obtained between September 2001 and October 2007 at the Kyushu Cancer Center, were reviewed in embedded whole-mount antegrade radical prostatectomy specimens with adenocarcinoma. Fifty-two cases were excluded from the investigation because of past hormonal therapy or incomplete sections. The subjects were Japanese, aged between 47 and 78 years (mean 66.8, median 68) and the value of the prostate-specific antigen ranged from 0.8 to $49.6 \mathrm{ng} / \mathrm{ml}$ (mean 10.2, median 7.5). The radical prostatectomy specimens were fixed in $10 \%$ neutral-buffered formalin for 48-96 h. Whole organ prostate specimens were serially sectioned perpendicular to the rectal surface at $5 \mathrm{~mm}$ intervals. The most caudal and cephalic sections were cut in sagittal planes at $5 \mathrm{~mm}$ intervals to assess the bladder neck and apical margins. The specimens were embedded in paraffin, and the sections were cut into $5 \mu \mathrm{m}$ slices and then stained with hematoxylin and eosin. The area of each tumor focus was determined by computer planimetry and multiplied by the section thickness. The calculated volume was multiplied by a factor of 1.33 to correct for tissue shrinkage in processing (2). In multifocal tumors the volumes of the foci were calculated to determine the radical prostatectomy tumor volume. Three groups $\left(<0.5 \mathrm{~cm}^{3}, \leq 0.5 \mathrm{~cm}^{3}<1 \mathrm{~cm}\right.$ and $\left.\geq 1 \mathrm{~cm}^{3}\right)$ were identified based on the total cancer volume, and a histological study was conducted on each group. Based on the 2005 International Society of Urological Pathology (ISUP) Consensus Conference on Gleason Grading of Prostatic Carcinoma (3), the pathological evaluations were performed by one pathologist. Statistical methods used included the Kruskal-Wallis test.

\section{Results}

In an evaluation of the Gleason primary pattern, 45 cases with a cancer volume of $<0.5 \mathrm{~cm}^{3}$, or $64.4 \%$ of the lesions, exhibited Gleason pattern 3, while Gleason pattern 4 was observed in $26.7 \%$; a total of $91.1 \%$. When lesions with Gleason pattern 5 were included, the Gleason primary pattern totaled $95.5 \%$ (Table I). Similarly, secondary Gleason patterns 3 and 4 were observed in 53.3 and $42.2 \%$ (a total of $95.5 \%$ ) of cases, respectively, for lesions with a cancer volume of $<0.5 \mathrm{~cm}^{3}$. The 
Table II. Summary of the Gleason primary pattern.

\begin{tabular}{lccccr}
\hline & \multicolumn{5}{c}{ Gleason primary pattern } \\
\cline { 2 - 5 } Cancer volume & 2 & 3 & 4 & 5 & Total \\
\hline$<0.5 \mathrm{~cm}^{3}$ & $2(4.4 \%)$ & $29(64.4 \%)$ & $12(26.7 \%)$ & $2(4.40 \%)$ & $45(23.0 \%)$ \\
$\leq 0.5 \mathrm{~cm}^{3},<1 \mathrm{~cm}^{3}$ & $0(0.0 \%)$ & $16(53.3 \%)$ & $13(43.3 \%)$ & $11(3.30 \%)$ & $30(15.3 \%)$ \\
$\geq 1 \mathrm{~cm}^{3}$ & $1(0.8 \%)$ & $38(31.4 \%)$ & $65(53.7 \%)$ & $17(14.00 \%)$ & $121(61.7 \%)$ \\
p-value & & $\mathrm{p}<0.01$ & $\mathrm{p}<0.01$ & $\mathrm{p}=0.08$ & \\
\hline
\end{tabular}

Table II. Summary of the Gleason secondary pattern.

\begin{tabular}{lcccrr}
\hline & \multicolumn{5}{c}{ Gleason secondary pattern } \\
\cline { 2 - 5 } Cancer volume & 2 & 3 & 4 & 5 & Total \\
\hline$<0.5 \mathrm{~cm}^{3}$ & $1(2.2 \%)$ & $24(53.3 \%)$ & $19(42.2 \%)$ & $1(2.2 \%)$ & $45(23.0 \%)$ \\
$\leq 0.5 \mathrm{~cm}^{3},<1 \mathrm{~cm}^{3}$ & $0(0.0 \%)$ & $11(36.7 \%)$ & $15(50.0 \%)$ & $4(13.3 \%)$ & $30(15.3 \%)$ \\
$\geq 1 \mathrm{~cm}^{3}$ & $1(0.8 \%)$ & $36(29.8 \%)$ & $55(45.5 \%)$ & $29(24.0 \%)$ & $121(61.7 \%)$ \\
p-value & & $\mathrm{p}=0.02$ & $\mathrm{p}=0.08$ & $\mathrm{p}<0.01$ & \\
\hline
\end{tabular}

Table III. Relationship between cribriform carcinoma classified as Gleason pattern 3 and total cancer volume.

\begin{tabular}{lccr}
\hline Cancer volume & GP3CC (+) & GP3CC (-) & Total \\
\hline$<0.5 \mathrm{~cm}^{3}$ & $0(0.0 \%)$ & $45(100.0 \%)$ & 45 \\
$\leq 0.5 \mathrm{~cm}^{3},<1 \mathrm{~cm}^{3}$ & $9(30.0 \%)$ & $21(70.0 \%)$ & 30 \\
$\geq 1 \mathrm{~cm}^{3}$ & $116(95.9 \%)$ & $5(4.1 \%)$ & 121 \\
\hline
\end{tabular}

GP3CC, Gleason pattern 3 cribriform carcinoma; $\mathrm{p}<0.01$.

Gleason secondary pattern included $97.7 \%$ when the lesions with Gleason pattern 5 were included (Table II). In addition, no cribriform carcinoma was identified in Gleason pattern 3 in lesions with a cancer volume of $<0.5 \mathrm{~cm}^{3}$ (Table III). In the group with a cancer volume $<0.5 \mathrm{~cm}^{3}$, both the Gleason primary and secondary patterns were consistent with a carcinoma with a small size acini. When the density of those acini was compared with that of ambient normal acini, it proved to be much higher (Fig. 1). With the increase in total cancer volume, Gleason primary pattern 4 and the cribriform carcinoma classified as Gleason pattern 3 increased significantly ( $p<0.01$; Tables I and III), while the Gleason primary pattern 3 alone decreased $(\mathrm{p}<0.01$; Table II). Over $95 \%$ of the total cancer volume $\geq 1 \mathrm{~cm}^{3}$ contain cribriform carcinoma classified as Gleason pattern 3 .

\section{Discussion}

We aimed to investigate the pattern in which prostatic carcinoma originates and how it invades tissue. Untreated radical prostatectomy specimens archived in this hospital were therefore histologically examined.
Initially the specimens were evaluated based on the 2005 ISUP Consensus Conference on Gleason Grading of Prostatic Carcinoma (3). McNeal et al reported that evaluation of the whole-tumor histological characteristics may contribute to a better appreciation of the role of histological differentiation compared with other factors in determining the behavior of prostate cancer (4). Hence, the total cancer volume was then estimated. The specimens were then classified into three groups based on the total cancer volume.

To demonstrate the original patterns of prostatic carcinoma, lesions with a cancer volume of $<0.5 \mathrm{~cm}^{3}$ were evaluated using the definitions of insignificant cancer described by Stamey et al (5). Gleason primary patterns 3 and 4 accounted for $91.1 \%$ of the smaller tumors, while Gleason secondary patterns 3 and 4 were found in $95.5 \%$ of the lesions. These data indicate that the classification of prostatic carcinoma with a cancer volume of $<0.5 \mathrm{~cm}^{3}$ is predominantly Gleason pattern 3 and 4 . In this group, Gleason pattern 3 did not exhibit a cribriform pattern and consisted of assembled acini, which were independent and smaller in size than those characteristic of Gleason patterns 1 or 2. Gleason pattern 4 exhibited independent and ill-defined acini and did not contain large cribriform acini. In other words, the acini of prostate carcinoma with a cancer volume of $<0.5 \mathrm{~cm}^{3}$ consisted mostly of independent acini of a small size. Furthermore, these acini proliferated without disrupting the structure of smooth muscle. The acini were quite dense in comparison to the surrounding non-neoplastic acini (Fig. 1). Based on these observations, it would appear that small acini of prostatic carcinoma are dense because they invade not only the surrounding acini and small ducts, but also the stroma at a quite early stage. Humphrey reported that the natural history of prostatic carcinoma begins with the invasion of prostatic carcinoma cells in the stroma. Most prostatic carcinomas fail to elicit a stromal response. Subsequently, the malignant acini 


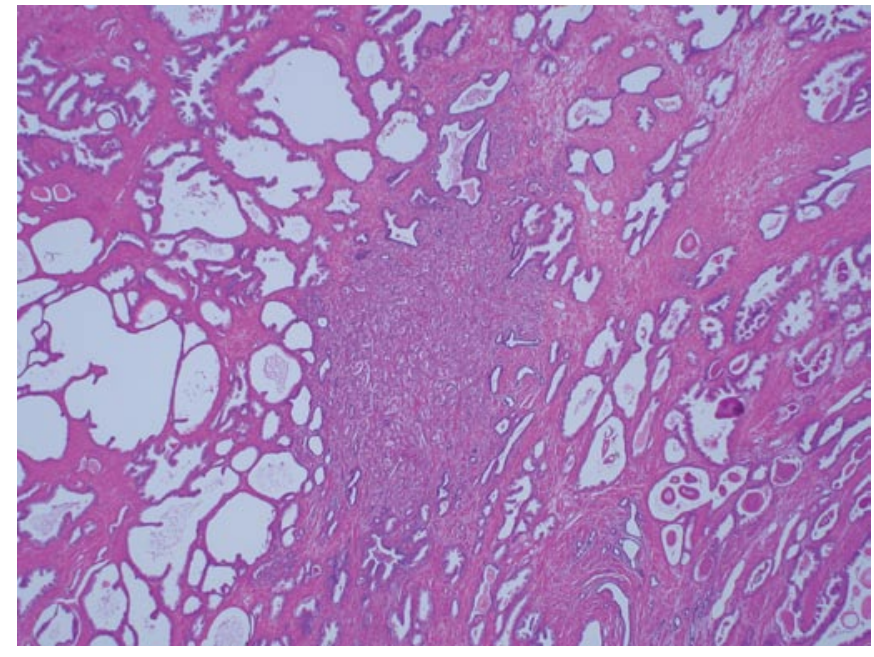

Figure 1. Dense prostatic carcinoma in comparison with non-neoplastic acini.

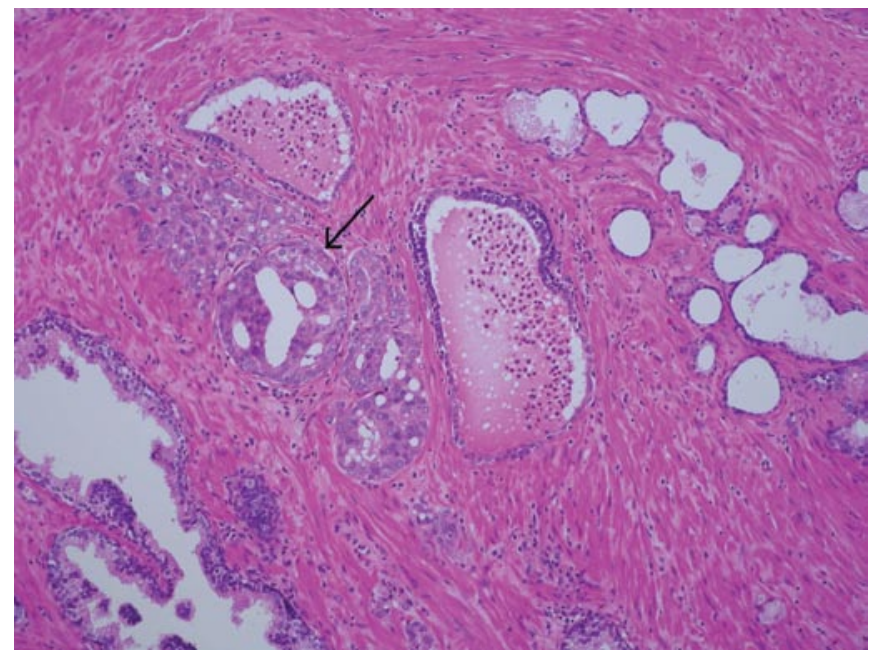

Figure 2. Gleason grade 3 cribriform carcinoma; rounded, well-circumscribed glands of the same size as normal glands (arrow).

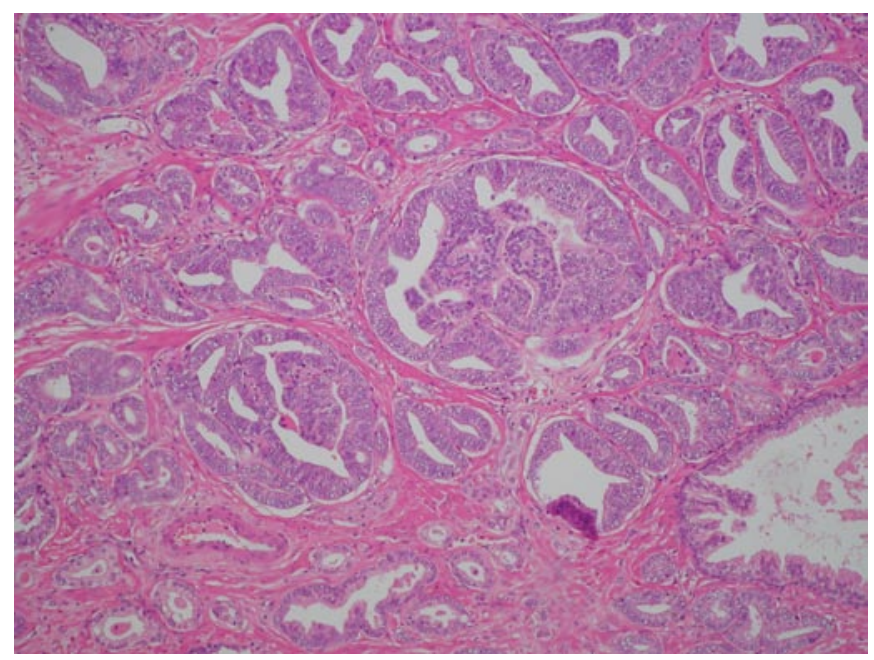

Figure 3. Cribriform carcinoma of Gleason pattern 4. Large cribriform acini and irregularities of the outer border of the cribriform glands are shown. appear to be embedded within normal-appearing fibromuscular stroma (6). These descriptions are consistent with observations in the present study. Prostatic carcinomas originate morphologically in independent small-sized acini. Therefore, prostatic carcinomas are dense in comparison with non-neoplastic acini because of the invasion not only into the surrounding acini and small ducts, but also in the stroma at a relative early stage.

The study also aimed to clarify how the mass of small acini increased by reviewing the changes in the histological features associated with increasing total cancer volume. The primary focus was on the cribriform pattern of the Gleason pattern 3 cribriform carcinoma in particular (Fig. 2). Cribriform carcinoma classified as Gleason pattern 3 was not observed in any of the 45 cases with a cancer volume of $<0.5 \mathrm{~cm}^{3}$. McNeal et al reported that the histological features of the cribriform grade 3 pattern based on Gleason's original illustrations (7-9) may often represent cancer growing within the lumens of preexisting ducts and acini rather than a pattern of invasive tumor (10-12). Within Gleason's original illustrations, cribriform pattern 3 is depicted as large cribriform acini. However, most of the cribriform patterns in this study were diagnosed to be Gleason pattern 4 (Fig. 3). The 2005 ISUP reported that it was the consensus that most of the cribriform patterns should be diagnosed as pattern 4 , with only rare cribriform lesions satisfying the diagnostic criteria for Gleason pattern 3. Moreover, the criteria used to diagnose Gleason pattern 3 were rounded, well-circumscribed glands of the same size as normal glands (3). In the present study, the proportion including cribriform carcinoma classified as Gleason pattern 3 increased significantly with the increase of cancer volume $(\mathrm{p}<0.01)$. Thus, $>95 \%$ of the total cancer volume $\geq 1 \mathrm{~cm}^{3}$ contain cribriform carcinoma classified as Gleason pattern 3. Based on this observation, the growth of the small acini of prostatic carcinoma within the lumens of preexisting ducts and acini is considered to increase the tumor volume.

It was thought that Gleason pattern 3 cribriform carcinoma expressed an invasion to the terminal acini or small ducts, since they were nearly equal to normal acini in size. In addition, it appeared that Gleason pattern 3 cribriform carcinoma expressed infiltrating preexisting acini and ducts that did not invade peripherally as the lesions were rounded and well-circumscribed. McNeal et al noted that with regard to the cribriform pattern, the relationship between total tumor volume and presence of cribriform elements was statistically significant $(\mathrm{p}<0.001)(11)$. The current results are consistent with those of McNeal et al. Therefore, it appears that the cribriform pattern of prostatic carcinoma categorized as Gleason pattern 3 is characteristic of tumors infiltrating the terminal ducts and acini, accelerating the increase of tumor volume. We estimate that the Gleason pattern 4 cribriform carcinoma may express invasion to larger acini and ducts in comparison with the Gleason pattern 3 cribriform carcinoma. As a result, we hypothesize that the Gleason pattern 4 cribriform carcinoma demonstrates the structure of the cribriform pattern which has either a large size or shows marginal irregularity.

In summary, the original pattern of prostatic carcinoma was mainly composed of small acini. In addition, the prostatic carcinoma infiltrated surrounding stroma at quite an early stage. This infiltration caused an increase in the tumor volume in both the stroma and preexisting acini and ducts. However, 
infiltration of the preexisting ducts and acini is considered to lead to a greater increase in the tumor volume than direct infiltration of the stroma.

\section{Acknowledgements}

The authors thank Mr. Brian Quinn for linguistic comments and help with the manuscript.

\section{References}

1. Ekman P, Adolfsson $\mathrm{J}$ and Gronberg H: The natural history of prostate cancer. Martin Dunitz, London, pp1-16, 1996.

2. Elgamal AA, Van Poppel HP, Van De Voorde WN, Van Dorpe JA, Oyen RH and Baert LV: Impalpable invisible stage T1c prostate cancer: characteristics and clinical relevance in 100 radical prostatectomy specimens - a different view. J Urol 157: 244-250, 1997.

3. Epstein JI, Allsbrook WC Jr, Amin MB, Egevad LL and the ISUP Grading Committee: The 2005 International Society of Urological Pathology (ISUP) Consensus Conference on Gleason Grading of Prostatic Carcinoma. Am J Surg Pathol 29: 1228-1242, 2005.
4. McNeal JE, Villers AA, Redwine EA, Freiha FS and Stamey TA: Histologic differentiation, cancer volume and pelvic lymph node metastasis in adenocarcinoma of the prostate. Cancer 66: 1225-1233, 1990

5. Stamey TA, Freiha FS, McNeal JE, et al: Localized prostate cancer: relationship of tumor volume to clinical significance for treatment of prostate cancer. Cancer 71: 933-938, 1993.

6. Humphrey PA: Natural history and mortality. In: Prostate Pathology. Amer Society of Clinical Pathology, Chicago, pp241-249, 2003.

7. Bailar JC III, Mellinger GT and Gleason DF: Survival rates of patients with prostatic cancer, tumor stage and differentiation: preliminary report. Cancer Chemother Rep 50: 129-136, 1966.

8. Gleason DF: Classification of prostatic carcinomas. Cancer Chemother Rep 50: 125-128, 1966.

9. Mellinger GT, Gleason D and Bailar JC III: The histology and prognosis of prostatic cancer. J Urol 97: 331-337, 1967.

10. Kovi J, Jackson MA and Heshmat MY: Ductal spread in prostatic carcinoma. Cancer 56: 1566-1573, 1985.

11. McNeal JE, Reese JH, Redwine EA, Freiha FS and Stamey TA: Cribriform adenocarcinoma of the prostate. Cancer 58: 1714-1719, 1986.

12. McNeal JE and Cheryl EM: Spread of adenocarcinoma within prostatic ducts and acini. Am J Surg Pathol 20: 802-814, 1996. 